\title{
Comparison of different solutions for blocking diode applications in a photovoltaic panel under varying ambient conditions
}

\author{
H.C. Neitzert ${ }^{1}$ and A. Astone $e^{1,2}$ \\ ${ }^{1}$ Department of Electrical Engineering \\ DIIIE, Salerno University \\ Via Ponte Don Melillo 1, 84084 Fisciano (SA) (Italy) \\ Phone number:+0039089 964304, fax number:+0039089 964218, e-mail: neitzert@unisa.it \\ 2 present address: \\ Telefon Italia Mobile (TIM) \\ Trieste (Italy) \\ Phone number:+0039 335 6339639,e-mail: aldo.astone@gmail.com
}

\begin{abstract}
We characterized a crystalline silicon based minimodule under varying ambient conditions, developed a PSPICE model for this panel, including temperature and irradiation dependence and applied this model to the simulation of the impact of a blocking diode under different ambient conditions. Different blocking diodes were examined, like germanium and silicon homojunction diodes and silicon Schottky diodes and compared to "intelligent" diodes, consisting of operational amplifiers with MOSFET switches. We calculated a strongly reduced power loss in a panel integrating the "intelligent" blocking diodes even when compared to silicon Schottky diodes with a rather low voltage drop.
\end{abstract}

\section{Key words}

Blocking diode, bypass diode, photovoltaics, circuit simulation, shadowing, intelligent diode, MOSFET

\section{Introduction}

A long lasting discussion regarding the sense of the integration of blocking or bypass diodes in solar panels $[1,2]$ did so far not come to a conclusive answer. For example it has been reported that bypass diodes have been responsible for failures in solar battery charging stations [3]. Under some ambient conditions, however, in particular under partial shadowing conditions of solar panels or solar fields or under non homogeneously distributed temperature conditions, without the use of this diodes, large power losses are measured due to non matching currents or voltages. On the other hand is the voltage drop of conventional diodes not negligible. With the development of low-cost analog circuitry and MOSFET's with extremely low on-resistance values, the realisation of "intelligent" diodes with almost no power losses becomes viable [4]. Regarding the use of traditional single diode solutions for blocking diode applications, different types of devices are employed. Mostly silicon based pn-diodes or Schottky diodes are used. In the case of high temperature environmental conditions, also $\mathrm{SiC}$ blocking diodes have been proposed [5]. Operation in a extremely wide temperature range between $-170^{\circ} \mathrm{C}$ and $270^{\circ} \mathrm{C}$ has been achieved in this latter case. This is of interest for example for space based photovoltaic systems. In the case of terrestrial systems, however, low-bandgap semiconductors should be more interesting because of the lower forward bias voltage drop. Historically germanium and selenium have been preceeding the nowadays dominating silicon as material for rectifying diodes. May be in the future, germanium can gain again some importance for blocking diode applications in PV panels.

\section{Results and Discussion}

As a first step, we sent a questionary to a number of solar panel producers and asked them, if, and in case of a positive answer, what kind of blocking or bypass diodes they integrated into their products. The responses, summarized in Table 1, indicated that only few producers integrated blocking diodes into their solar panels, while some more integrated bypass diodes. Most popular diodes were silicon Schottky diodes because of the lower voltage drop as compared to silicon pn-diodes, as mentioned before.

\begin{tabular}{|c|c|c|c|}
\hline $\begin{array}{c}\text { blocking } \\
\text { diode }\end{array}$ & $\begin{array}{c}\text { bypass } \\
\text { diode }\end{array}$ & diode type & manufacturer \\
\hline no & yes & 80 SQ045 & Solar-Fabrik \\
\hline optional & yes & Schottky & $\begin{array}{c}\text { United Solar } \\
\text { Ovonics Corp. }\end{array}$ \\
\hline no & no & - & First Solar LLC \\
\hline no & no & - & $\begin{array}{c}\text { Solar Integrated } \\
\text { Technologies }\end{array}$ \\
\hline no & yes & $\begin{array}{c}\text { module } \\
\text { dependent } \\
\text { (Silicon) }\end{array}$ & Shell Solar B.V. \\
\hline
\end{tabular}

Table 1 Results of the manufacturer interviews regarding the use of blocking and bypass diodes 


\section{Characterization of a silicon PV minimodule}

Subsequently we characterized a commercial crystalline silicon photovoltaic minimodule (see Fig.1) under varying ambient conditions. In particular, we measured the minimodule at ambient temperature between $30^{\circ} \mathrm{C}$ and $60^{\circ} \mathrm{C}$ and used three different irradiance values (illumination with a halogen lamp). It should be noted that under standard irradiation conditions (AM1.5G) a conversion efficiency of $12.1 \%$ has been measured for the minimodule. In Fig. 2 for example the current-voltage characteristics at different temperatures under irradiation with a halogen lamp with an resulting irradiance of $2105 \mathrm{~W} / \mathrm{m}^{2}$ is shown.

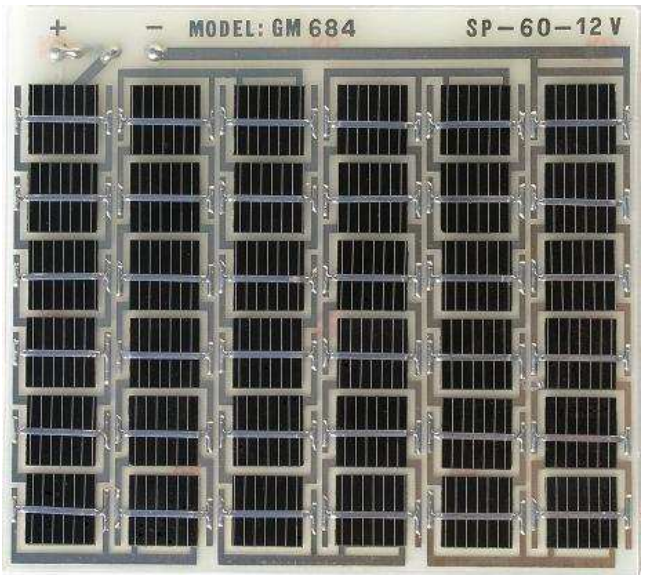

Fig.1 Characterized silicon minimodule

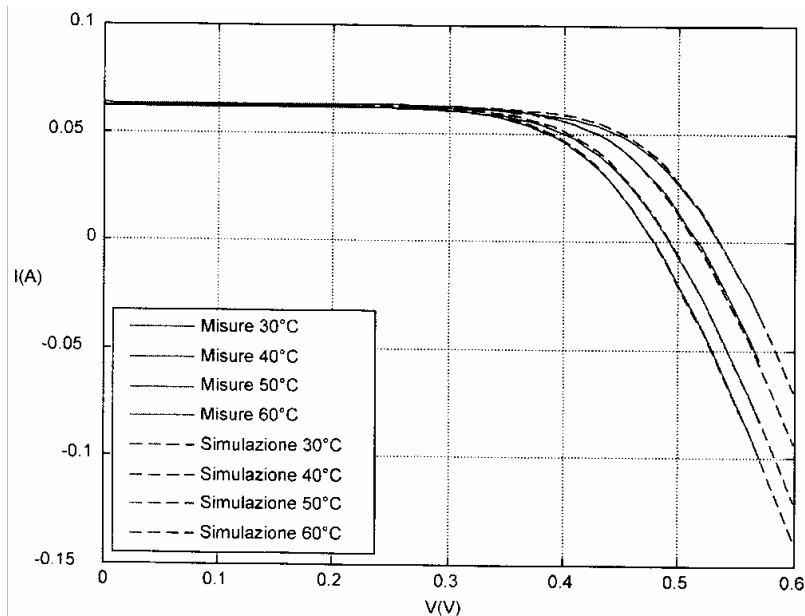

Fig.2 Measurement and simulation of the temperature dependent (between $30^{\circ} \mathrm{C}$ and $60^{\circ} \mathrm{C}$ in $10^{\circ} \mathrm{C}$ steps) current-voltage characteristics under irradiation with $2105 \mathrm{~W} / \mathrm{m}^{2}$ of a single diode of the above shown minimodule

For a single silicon PV cell of the minimodule, based on the measurements that are partially shown in Fig.2, a PSPICE model (see Fig. 3) has been developed, that accounts also for temperature and irradiance variations.
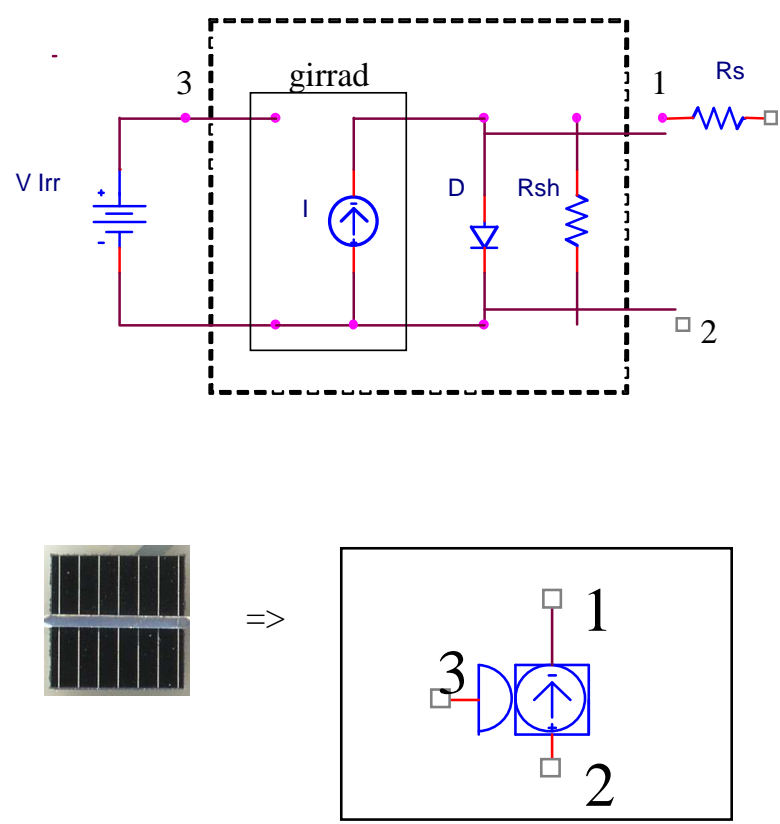

Fig.3 PSPICE model of single cell, taken into account the solar irradiation condition and temperature behaviour

Characterization of different types of blocking diodes Subsequently we characterized 4 different types of possible blocking diodes: a conventional high power silicon diode (1N4007) and a silicon based Schottky diode (1N5818) and additionally 2 different "historical" lowbandgap semiconductor diodes (AEG selenium rectifier) and a germanium diode (OA81). It should be noted, that the OA81 diode is a low power device and has been only included because we did not have access to commercial germanium power diodes. Other types of high power germanium diodes could, however, in the future be an interesting alternative to conventional silicon diodes.

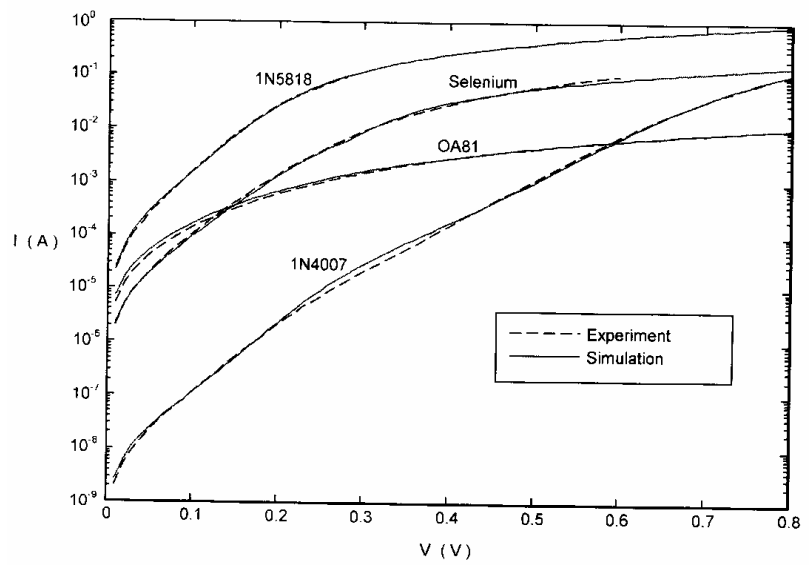

Fig.4 Comparison of the measured and simulated forward bias current-voltage characteristics at room temperature of 4 different commercial diodes. 
In Fig. 4 the measured and simulated forward bias diode current-voltage characteristics at room temperature are displayed. The superior performance of the Schottky diode as compared to the silicon pn-diode is clearly seen. As expected we find that also the selenium diode has a lower voltage drop for a given current value when compared to the silicon pn-diode. The germanium diode (OA81) suffers from the high series resistance and has therefore the worst behaviour of the 4 diodes for high forward current values.

For every diode type also a complete characterization at 4 different temperatures has been done. As an example in Fig. 5 the current-voltage characteristics between $30^{\circ} \mathrm{C}$ and $60^{\circ} \mathrm{C}$ of the Schottky diode are shown and compared to the PSPICE simulation of the same diode. A good agreement between measured and simulated characteristics has been achieved.

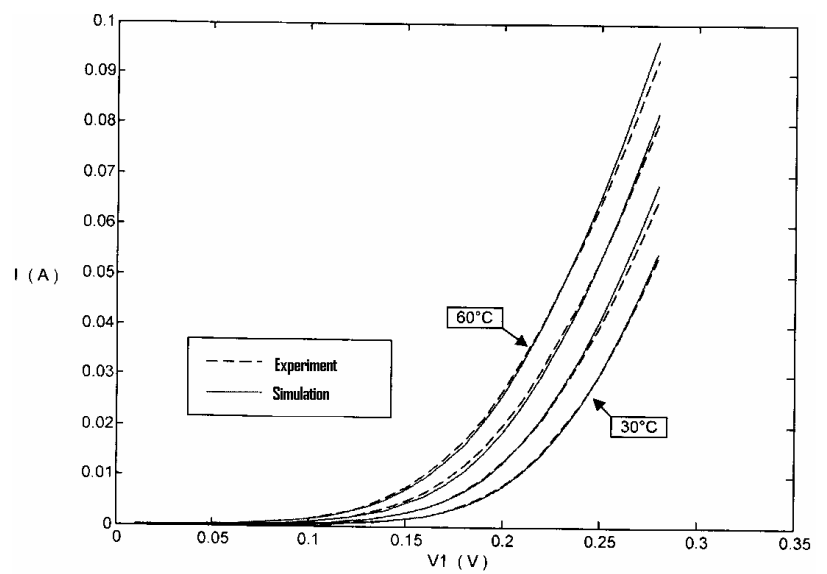

Fig.5 Measurement and simulation of the temperature dependent current-voltage characteristics of the 1N5158 Schottky diode between $30^{\circ} \mathrm{C}$ and $60^{\circ} \mathrm{C}$ (in $10^{\circ} \mathrm{C}$ steps).

\section{Comparison of power losses for different blocking diodes}

Subsequently a simulation of the power losses at $30^{\circ} \mathrm{C}$ and $60^{\circ} \mathrm{C}$, when using the 4 different blocking diodes has been performed.

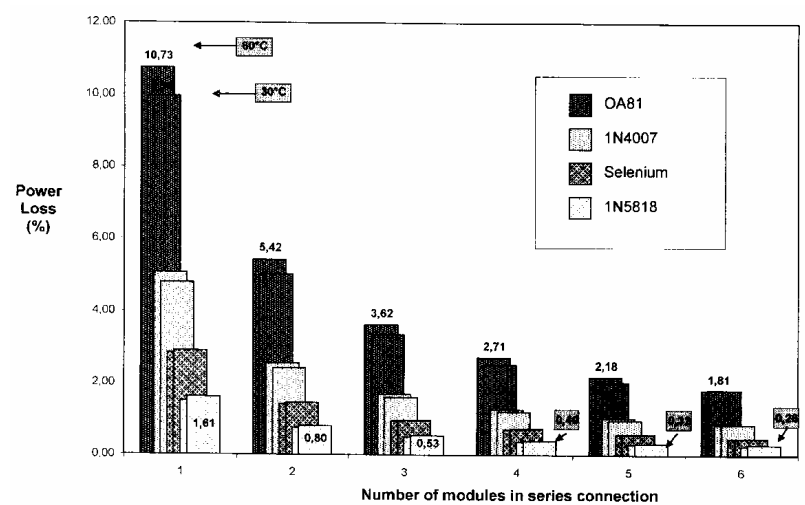

Fig.6 Power loss as a function of the number of series connected solar cells for different types of blocking diodes at two different ambient temperatures $\left(30^{\circ} \mathrm{C}\right.$ and $\left.60^{\circ} \mathrm{C}\right)$..
The results as a function of the number of series connected silicon solar cells are shown in Fig. 6 for a given irradiance. The use of Schottky diodes (type "1N5818") instead of silicon pn-diodes (Type "1N40007") resulted in a factor of three lower power losses as well at $30^{\circ} \mathrm{C}$ and at $60^{\circ} \mathrm{C}$ ambient temperatures.

\section{Intelligent diode with low voltage drop}

A very strong further gain regarding the reduced power loss (see Fig.7), has been achieved using a combination of a low power operational amplifier (type “OP290”) with a low on-resistance MOSFET (type "IRF630"), working as "intelligent" diode with low own power consumption and very low voltage drop in forward direction. The circuit of the "intelligent" blocking diode and the insertion into the solar panel are shown in Fig.6.

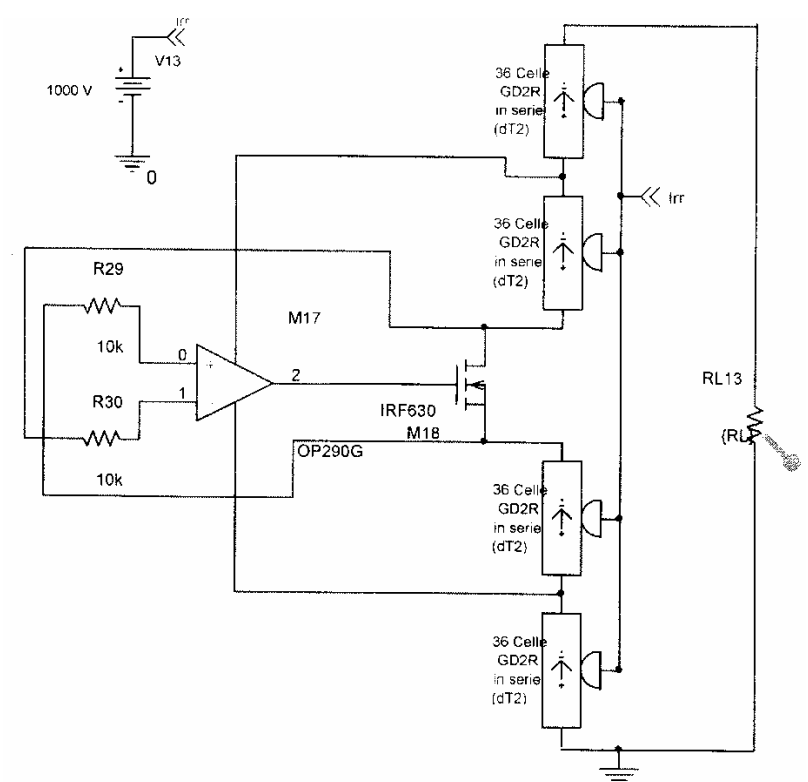

Fig.6 Configuration of an "intelligent" blocking diode inserted in a PV module

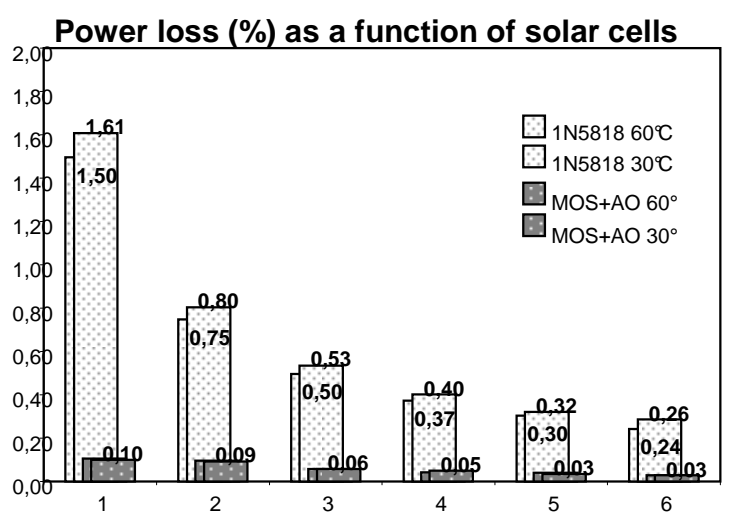

Fig.7 Power loss as a function of the number of series connected solar cells for a Schottky diode and an "intelligent" diode at two different temperatures 


\section{Conclusions}

A comprehensive simulation of the impact of the blocking diode choice on the power losses of a silicon photovoltaic panel has been done. The simulation parameters of the silicon panel and of the investigated blocking diodes have been obtained by extraction of the device parameters from electrical measurements under different temperatures and irradiation conditions. An appreciable reduction of the power losses have been obtained using a silicon Schottky diode instead of a silicon pn-diode. Also the use of a "historical" low-bandgap selenium rectifier resulted in reduced power losses as compared to the silicon pn-diode. Simulation showed, that a strong further improvement can be achieved when, instead of the silicon Schottky blocking diode, an "intelligent" diode, consisting of an operational amplifier in combination with a power MOSFET is used.

\section{References}

[1] S.J. Durand, "Attaining a 30-year photovoltaic system lifetime: The BOS issues", Progress in Photovoltaics, Vol.2, (2007), pp.107-113

[2] J.C. Wiles and D.L. King, "Blocking diodes and Fuses in Low-Voltage PV Systems", in Proc. of the $26^{\text {th }}$ IEEE PVSC, Anaheim (1997), pp. 1105-1108

[3] C. Greacen and D. Green, Solar Energy Materials \& Solar Cells, Vol. 70 (2001), pp. 141-149

[4] www.icbase.com/pdf/ONS/ONS24940605.pdf

[5] E. Maset, E. Sanchis-Kilders, J. Jordan, J. Bta. Ejea, A. Ferreres, J. Millan, P. Godginon and X. Jorda, Proc. Of the 2009 Spanish Conf. on Electron Devices, Santago de Compostela (2009), pp. 443-446 